\title{
Evaluation Model for Teaching Quality of Physical Education 體育教學品質評估模式
}

\author{
Chang-Hung HUNG \\ Department of Leisure Industry Management, \\ National Chin-Yi University of Technology, TAIWAN \\ Jung-Chi SU \\ Office of Physical Education, \\ National Chin-Yi University of Technology, TAIWAN \\ Wen-Tzung CHEN \\ Department of Information Management, \\ Nanya Institute of Technology, TAIWAN \\ 洪彰鴻 \\ 台灣國立勤益科技大學休閒產業管理系
}

\section{蘇第基}

台灣國立勤益科技大學體育室

\author{
陳文宗
}

台灣南亞技術學院資訊管理系

\begin{abstract}
Abtract
This study seeks to build an evaluation model for physical education. Based on the concept of physical education quality, the questionnaire for physical education is constructed. Binominal probability distribution theory is applied to evaluate the proportion of the degree of importance and satisfaction for physical education. To evaluate the quality of physical education, the PZB concept proposed by Parasurman, Zeithaml and Berry (1985) is used to test the difference between the proportion of the degree of importance and satisfaction. Each quality performance item of education could be evaluated by figuring out the difference between the proportion of the degree of importance and satisfaction, therefore the improvement or correction could be taken if needed.
\end{abstract}

\section{摘 要}

本研究旨在建構一套體育教學品質評量模式, 首先以體育教學品質概念作為體育教學品質問卷建構的基礎, 並以二項分配理 論衡量體育教學要項的重視度比例與滿意度比例, 接著以PZB服務品質落差的概念, 檢驗滿意度比例與重視度比例的落差, 來評 估體育教學品質的良窟。教學單位只須依教學品質要項的滿意度比例及重視度比例的落差, 即可評量出各教學要項的品質績效, 並針對須要改進的要項進行改善。 


\section{前言}

由於社會日趨開放與多元發展, 如何提升教學品質一直 是教育界所關注的焦點。隨著品質時代的來臨, 品質的意義 與追求已廣泛的受到企業界的重視, 現今更是拓展至非營利 組織，造成教育界一股新的改革風潮（陳育君，2002）。眾 所週知德、智、體、群、美等五育為我國教育的內容, 體育 隸屬教育的一環，因此體育教學也必須融入此一風潮，追求 卓越的教學品質。

教育品質的提升首重教學品質的確保, 而提升教學品 質的首要工作為進行教學品質的評量, 然後依照評量結果 進行擬定品質提升計畫。簡紅珠（1993）指出近年來學生參 與教學評鑑，已經成為大專院校維持教學品質的評鑑途徑之 一。的確, 在講求成本效益的今日, 學生有權利要求獲得與 其所付成本相當品質的課程與教學, 而教師也必須盡義務提 供學生良好的教學品質。張俊郎、周昭宇 (2001) 認為教育 事業可將之歸類為製造業, 亦可視之為服務業。從製造業的 角度來看教育, 則學生為學校所生產的產品, 而消費者則是 社會各產業。從服務的角度來看教育, 學校的教育是否成 功, 在於學校是否能提供良好教學品質。學校若能提供良好 教學品質, 也就是給學生（消費者）良好的服務。如此一 來, 便衍生出學生成為學校的顧客, 由顧客的滿意度來反映 服務（教學品質）的好壞。吳清山（2001）也指出藉由全面 品質管理的應用, 將教育視為一種「服務」, 並把學生視為 「顧客」亦即強調學生本位。學生如為顧客, 那麼學校所開 設的課程則為商品, 學校的行政措施應為售後服務。所以學 校所提供的教學也是屬於服務的範疇, 也必須強調品質。吳 春雨（2004）也強調, 談論教育品質的提升, 首要碓認教育 的顧客, 方能建立教育目標。因此, 以服務品質的的概念為 出發, 將學生視為教育的顧客, 由學生的角度來評量教學品 質, 為本研究的出發點。
由於二十一世紀已經是邁入服務化的社會，黄勇富 （1999）認為教育事業應可歸於服務業，國內在服務品質 的提升上, 大多學者均由PZB服務品質模式著手。江義平 （2000）指出，當企業界及學術界紛紛對「服務品質」進行 研究探討時, 許多非營利事業亦開始重視此一課題的影響。 其中教育機構的服務品質已成為近年來社會大眾的討論焦點 之一。在教育研究領域已有許多研究應用PZB服務品質概念 來探討教學服務品質（周碩樑，1999；王俊貴，2001；陳育 君, 2002 ; 簡君蓉, 2002 ; 邱子玲, 2003）洪彰鴻, 蘇榮基 （2005a）首先應用PZB服務品質概念來探討體育教學品質。

饒達欽與鄭增財（1997）認為要使教學品質的提升可以 落實, 必須建立公信力的教學品質指標, 並發展出可行的評 鑑模式。因此, 本研究的主要目的為發展一套可行的教學品 質評量模式。首先以洪彰鴻、蘇榮基（2005）所建構的體育 教學品質模式為主軸, 接著應用二項分配的應用及PZB服務 品質落差的概念, 來衡量體育教學品質, 最後定出一套檢定 流程以作為推論的依據。本研將其定義為「體育教學品質評 量模式」，提供給體育教學品質評量與相關研究之參考。

\section{體育教學品質模式}

Parasurman・Zeithaml and Berry（PZB）等學者於 1985年發表「服務品質概念性模式」（Conceptual Model of Service Quality），他們認為顧客服務品質水準可以由 顧客對服務要項的期望及其服務後的實際感受來衡量, 也就 是從顧客期望服務與知覺服務間的差距來建立顧客服務品質 的知覺系統。此模式主要在強調顧客是服務品質的決定者, 服務品質是由服務接受者的期望與實際感受之間的落差來決 定，在服務產生與服務傳遞過程中有5個落差存在而形成5個 大落差（Gap）。洪彰鴻、蘇榮基（2005a）以PZB「服務品 質概念性模式」為主軸, 融入體育教學活動特質, 建構「體 育教學品質模式」（圖1），以作為衡量體育教學品質理論 基礎。

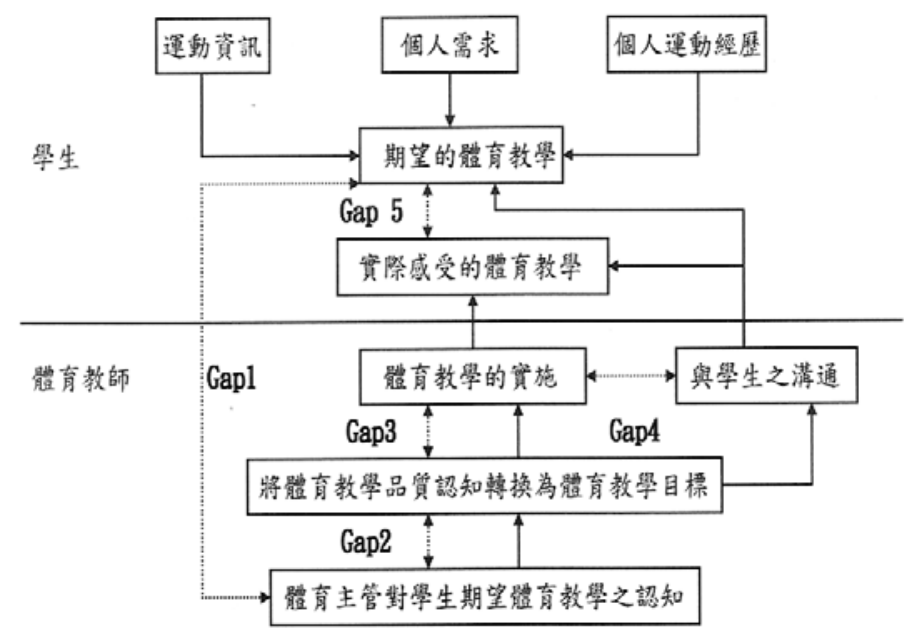

圖1. 體育敎學品質模式 (洪彰鴻、蘇榮基，2005a) 
洪彰鴻、蘇榮基（2005a）依據「體育教學品質模 式」，説明體育教學服務產生與傳遞間落差 (Gap) 形成的 變項説明如下：

落差1：「學生期望的體育教學」與「體育主管對學生期望 體育教學認知」間的差距。

落差2：「體育主管對學生期望體育教學認知」與「體育主 管將學生對體育教學品質認知轉換為體育教學 目標」間的差距。

落差3：「體育教學目標」與「體育教學的實施」間的差 距。

落差4：「體育教學的實施」與「學生溝通」間的差距。

落差5：「學生期望的體育教學品質水準」與「實際感受的 體育教學品質水準」間的差距, 也就是體育教學服 務品質差距。

根據PZB服務品質模式, 不論哪一類性的服務業, 如 要滿足顧客的需要, 就必須滿足此模式中的 5 道品質落差 距。每一道差距都會影服務品質, 各差距間的關係為 $\mathrm{Gap} 5$ = $\mathrm{f}$ (Gapl, Gap2, Gap3, Gap4), 其中Gap1, Gap2, Gap3，Gape4來自服務提供者，起因於組織內部的問題。 Gap5是由服務接受者所決定, 導因於顧客的期望與實際知 覺得落差。要使顧客對服務品質滿意就必須縮小Gape5的落 差, 服務品質的水準是由Gap5 的大小和方向來決定的。就 體育教學品質而言, 暫體育教學品質模式中如有落差存在, 將造成體育教學品質不佳。所以, 如果能消除模式中的落差 或縮小落差, 將有助於教學品質的提升。

PZ B 接著於 1988 年再提出服務品質五大構面分別 為實體性（Tangibles）、可靠性（Reliability）、反應 性（Responsiveness）、保證性（Assurance）、體貼性 (Empathy), 由此五大構面發展出可供實證研究的服 務品質「SERVQUAL」量表。洪彰鴻、蘇榮基(2005)以 $\lceil$ SERVQUAL」量表五大構面為基處並考量體育教學的內 容與特性，來説明體育教學品質五大構面的內涵如下：

1. 實體性（Tangibles）：指在體育教學過程中, 學生所使 用的運動場館、設備及器材等。

2. 可靠性 (Reliability) : 指在體育教學活動中, 學生能呴 學習正確的運動技能與常識, 也就是教師必須具備指導 學生運動技能學習的教學方法

3. 反應性 (Responsiveness) : 指在體育教學過程中, 教師 能夠迅速協助學生解決問題與立即的需求。

4. 保證性（Assurance）：指教師具備在體育教學所需的 運動技能與專業知識, 能夠以親切的態度來進行教學活 動, 讓學生在學習過程中有安全感並能呴獲得適時的鼓 勵。
5. 體貼性（Empathy）：指在體育教學過程中，教師對於 學生能夠提供特別的關心，尤其是有特殊需求的學生。

洪彰鴻、蘇榮基（2005）首先以PZB「服務品質概念性 模式」，建構「體育教學品質模式」，以及體育教學品質內 涵, 以作為衡量體育教學品質理論基礎, 並且有後續的相關 研究與實證 (洪彰鴻, 2004; 洪彰鴻、李城忠, 2004 ; 洪彰 鴻, 蘇榮基, 2005b; 洪彰鴻, 徐欽賢, 2005 ; 伍木成, 梁 隨燕，洪彰鴻，謝武進，2006），顯示體育教學品質模式的 可行性。所以, 本文將體育教學品質模式、體育教學品質落 差、體育教學品質構面等三大體育教學品質要素定義為「體 育教學品質概念」做為評量體育教學品質的內涵。

\section{體育教學品質評量}

Parasurman`Zeithaml and Berry（1991）指出, 服 務品質（Quality）的好壤是由顧客對服務的認知（Perception）和顧客對服務的期望（Expection）的差距來決定， 當Quality = Perception - Expection $>0$ 時, 此時顧客對於 服務的實際知覺高於期望, 表示品質是令人滿意的, 而當 Quality $=$ Perception - Expection $<0$, 此時顧客對於服務 的期望高於實際知覺, 表示品質是令人不滿意的。當服務品 質不佳時表示服務品質有缺口存在, 必須檢視每一道服務品 質缺口, 並提出改善計畫以消弭服務品質缺口提升服務品 質。品質是針對不同的顧客進行服務品質要項之滿意度與重 視度的評估, 所以教學品質應該是學校的教學能夠滿足教育 顧客的需要與期望。因此, 本文參考PZB服務品質落差的概 念, 來評量體育教學品質要項的重視度與滿意度以了解體育 教學品質水準。由於每個人的需求與期望差異性很大, 所以 不同的學生對於教學品質要項的滿意度與重視度的認知也會 有所不同。

在實務上, 對於滿意度與重視度的評估通常會以問卷調 查為工具。陳謙東 (2000) 認為, 一般評鑑量表有許多的設 計方式, 如兩種選項、四種選項、五種選項等。評鑑單位除 了希望評鑑結果正確外, 更希望評鑑的方法簡易且實用, 否 則評鑑結束後的分析工作, 就會令人厭煩, 使人不願意繼續 評鑑後的工作。因此, 評鑑量表無須太多的選項, 若選項太 多, 除了分析起來褑雜性增加外, 恐怕評鑑者對其標準都會 不好拿捏。所以, 評鑑時若能儘量利用兩種、四種選項的量 表來評鑑，再加上有效且正確的統計方法去分析，不僅可以 達到評鑑的目的, 亦可以得到較精確的評鑑結果。所以, 本 研究採二等量表格式, 應用二項分配的方法作為評量教學品 質水準的工具，問卷形式如表1所示：

假設問卷的要項有 $\mathrm{m}$ 項, 我們可以就學生對問卷要項的 滿意程度與重視程度來衡量教學品質。在合理的假設下, 學 生在各個要項中若重視比例愈多, 代表學生對教學要項的期 望越高; 學生在各個要項中若滿意比例愈多, 代表代表學生 
對教學要項的滿意度越高, 也就是教師的教學越能滿足學生 的期望。如此教師的教學品質就必須滿足學生的期望。本研 究所著重的是以數量表示式來做決策, 而採用比例的優點是
可代表一相對關係而非絕對關係。如問卷評量結果滿意比例 高於重視度比例, 表示教學品質愈佳; 反之, 滿意比例低於 重視度比例, 則表示教學品質愈差。

\section{表 1. 二項分配問卷形式}

\begin{tabular}{ccccc}
\hline 呚學要項 & 重視 & 不重視 & 滿意 & 不滿意 \\
\hline 1 & $\square$ & $\square$ & $\square$ & $\square$ \\
2 & $\square$ & $\square$ & $\square$ & $\square$ \\
$:$ & $:$ & $:$ & $:$ & $:$ \\
$j$ & $\square$ & $\square$ & $\square$ & $\square$ \\
$:$ & $:$ & $:$ & $:$ & $:$ \\
$\mathrm{m}$ & $\square$ & $\square$ & $\square$ & $\square$ \\
\hline
\end{tabular}

\section{滿意度比例 $p^{x}$ 與重視度比例 $p^{y}$ 的估計}

由於母體的滿意度比例與重視度比例是未知的, 因此必 須經由抽樣來估計。若令隨機變數X代表滿意度 $\mathrm{Y}$ 代表重視 度, $\left\{X_{1}, \ldots ., X_{n}\right\},\left\{Y_{1}, \ldots, Y_{n}\right\}$ 是我們從常態分配 之母體随機抽出樣本大小為 $\mathrm{n}$ 的隨機樣本, 接著訂意隨機變 數 $X_{i j}, Y_{i j}$ 如下:

$X_{i j}=\{1,0\}, 1$,表示第i個人第 $\mathrm{j}$ 個選擇 “滿意” ; 0 , 表示 第 $\sum_{i=1}^{n} X_{i j}=X_{j} \quad$, 表示第j個選項選擇滿意的人數。

$\sum_{i=1}^{n} \sum_{j=1}^{m} X_{i j}=X \quad$, 表示回答滿意的總人數。

$\hat{p}_{. j}^{x}=\frac{X_{. j}}{n}$, 表示第 $\mathrm{j}$ 個選項選擇滿意的比例。

$\hat{p}^{x}=\frac{X}{m}=\bar{X}$, 表示回答滿意的總比例。

$p^{x}$, 表示滿意度母體比例。

我們以 $\hat{p}^{x \text { 來估計 }} p^{x}$, 表 2 為 $\mathrm{m}$ 個教學要項的 $\mathrm{n}$ 個滿意 度觀察值樣本説明。

表 2. m個教學品質要項的n個滿意度觀察值

\begin{tabular}{cccc}
\hline 教學要項 & 樣本資料 & $X_{j}$ & $\hat{p}_{. j}^{x}$ \\
\hline 1 & $X_{11}, X_{21}, \ldots X_{n 1}$ & $X_{.1}$ & $\hat{p}_{.1}^{x}$ \\
2 & $X_{12}, X_{22}, \ldots X_{n 2}$ & $X_{2}$ & $\hat{p}_{.2}^{x}$ \\
$\vdots$ & $\vdots$ & $\vdots$ & $\vdots$ \\
$j$ & $X_{1 j}, X_{2 j}, \ldots X_{n j}$ & $X_{j}$ & $\hat{p}_{j}^{x}$ \\
$\vdots$ & $\vdots$ & $\vdots$ & $\vdots$ \\
$m$ & $X_{1 m}, X_{2 j}, \ldots X_{n m}$ & $X_{m}$ & $\vdots$ \\
& & $\hat{p}_{m}^{x}$ \\
\hline & & $X=\sum_{i=1}^{n} \sum_{j=1}^{m} X_{i j}$ & $\hat{p}^{x}=\frac{X}{n m}=\bar{X}$
\end{tabular}


$Y_{i j}=\{1,0\}, 1$,表示第 $i$ 個人第 $j$ 個選擇“重 視”; 0 ,表示第 $i$ 個人第 $j$ 個選擇“不重視”, $i=1,2, \ldots \ldots n ; j=1,2 \ldots \ldots m$ $\sum_{i=1}^{n} Y_{i j}=Y_{j}$, 表示第 $j$ 個選項選擇重視的 人數。

$\sum_{i=1}^{n} \sum_{j=1}^{m} Y_{i j}=Y$,表示回答重視的總人數。 $\hat{p}_{. j}^{y}=\frac{Y_{j}}{n}$,表示第 $j$ 個選項選擇重視的比例。
$\hat{p}^{y}=\frac{Y}{n m}=\bar{Y}$, 表示回答重視的總比例。

$p^{y}$, 表示重視度母體比例。

我們以 $\hat{p}^{y}$ 來估計 $p^{y}$, 表 3 爲 $m$ 個教學 要項的 $n$ 個重視度觀察值樣本說明。

表 3. m個教學品質要項的n個重視度觀察值

\begin{tabular}{cccc}
\hline 教學要項 & 樣本資料 & $Y_{j}$ & $\hat{p}_{j}^{y}$ \\
\hline 1 & $Y_{11}, Y_{21}, \ldots . Y_{n 1}$ & $Y_{1}$ & $\hat{p}_{1}^{y}$ \\
2 & $Y_{12}, Y_{22}, \ldots . Y_{n 2}$ & $Y_{2}$ & $\hat{p}_{2}^{y}$ \\
$\vdots$ & $\vdots$ & $\vdots$ & $\vdots$ \\
$\vdots$ & $\vdots$ & $\vdots$ & $\vdots$ \\
$j$ & $Y_{1 j}, Y_{2 j}, \ldots . Y_{n j}$ & $Y_{j}$ & $\hat{p}_{. j}^{y}$ \\
$\vdots$ & $\vdots$ & $\vdots$ & $\vdots$ \\
$\vdots$ & $\vdots$ & $\vdots$ & $\vdots$ \\
$m$ & $Y_{1 m}, Y_{2 j}, \ldots Y_{n m}$ & $Y_{. m}$ & $\hat{p}_{. m}^{y}$ \\
\hline
\end{tabular}

令滿意度母群體分配為 $X \sim \operatorname{Bernoulli}\left(p^{x}\right)$, 重視度 母群體分配為 $Y \sim \operatorname{Bernoulli}\left(p^{\dot{y}}\right)$, 則 $\hat{p}^{x}, \hat{p}^{y}$ 是觀測值的樣 本平均數, 所以 $\hat{p}^{x}, \hat{p}^{y}$ 之抽樣分配的期望值及變異數分別為

$$
\begin{aligned}
& E\left(\hat{p}^{x}\right)=p^{x}, V\left(\hat{p}^{x}\right)=\frac{p^{x}\left(1-p^{x}\right)}{n^{x}} ; \\
& E\left(\hat{p}^{y}\right)=p^{y}, V\left(\hat{p}^{y}\right)=\frac{p^{y}\left(1-p^{y}\right)}{n^{y}}, \text { 也就是 } \\
& \hat{p}^{x} \approx N\left(p^{x}, \frac{p^{x}\left(1-p^{x}\right)}{n^{x}}\right) ; \hat{p}^{y} \approx N\left(p^{y}, \frac{p^{y}\left(1-p^{y}\right)}{n^{y}}\right)
\end{aligned}
$$

當 $n^{x}, n^{y}$ 夠大時, $\hat{p}^{x}, \hat{p}^{y}$ 會近似常態分配, 根據中央 及限定理可知

$$
\frac{\hat{p}^{x}-p^{x}}{\sqrt{p^{x}\left(1-p^{x}\right) / n^{x}}} \approx N(0,1)
$$

$$
\frac{\hat{p}^{y}-p^{y}}{\sqrt{p^{y}\left(1-p^{y}\right) / n^{y}}} \approx N(0,1)
$$

近似標準常態分配。由於 $p^{x}, p^{y}$ 未知, 所以變異數 $V\left(\hat{p}^{x}\right), V\left(\hat{p}^{y}\right)$ 亦未知, 而以其估計量 $S^{2}\left(\hat{p}^{x}\right), S^{2}\left(\hat{p}^{y}\right)$ 代替之, 所以

$$
S^{2}\left(\hat{p}^{x}\right)=\frac{\hat{p}^{x}\left(1-\hat{p}^{x}\right)}{n^{x}} ; S^{2}\left(\hat{p}^{y}\right)=\frac{\hat{p}^{y}\left(1-\hat{p}^{y}\right)}{n^{y}}
$$

進一步, 則可求得 $p^{x}, p^{y}$ 的 $100(1-\alpha) \%$ 之近似 信賴區間篇

$$
\begin{aligned}
& \hat{p}^{x}-z_{\alpha / 2} \sqrt{\frac{\hat{p}^{x}\left(1-\hat{p}^{x}\right)}{n^{x}}}<p^{x}<\hat{p}^{x}+z_{\alpha / 2} \sqrt{\frac{\hat{p}^{x}\left(1-\hat{p}^{x}\right)}{n^{x}}} ; \\
& \hat{p}^{y}-z_{\alpha / 2} \sqrt{\frac{\hat{p}^{y}\left(1-\hat{p}^{y}\right)}{n^{y}}}<p^{y}<\hat{p}^{y}+z_{\alpha / 2} \sqrt{\frac{\hat{p}^{y}\left(1-\hat{p}^{y}\right)}{n^{y}}}
\end{aligned}
$$




\section{滿意度比例 $p^{x}$ 與重視度比例 $p^{y}$ 落差之檢定}

依照PZB服務品質落差理論當Quality=Perception -Expection > 0時, 表示品質不佳, 而當Quality = Perception-Expection $<0$, 表示品質優良。所以只要計 算滿意度比例 $p^{x}$ 與重視度比例 $p^{y}$ 的落差就可以了解教學品 質的好壤。而由於研究數據是以抽樣方式取得, 必須考量抽 樣誤差的因素。因此, 對於 $\mathrm{m}$ 個教學品質要項, 滿意度比例 $p^{x}$ 與重視度比例 $p^{y}$ 如有落差存在, 其落差是否有統計上的 意義, 則必須進行統計檢驗來判斷。所以, 我們必須假設滿 意度比例 $p^{x}$ 必須是不大於重視度比例 $p^{y}$, 其假設檢定程序 如下:

擬定虛無假設及對立假設：

$$
\begin{aligned}
& H_{0}: p^{x}-p^{y} \leq 0 \\
& H_{a}: p^{x}-p^{y}>0
\end{aligned}
$$

其檢定統計量爲

$$
p^{x}-p^{y}=\frac{\sum x}{n^{x}}-\frac{\sum y}{n^{y}}
$$

如 $H_{0}$ 临真實,檢定統計的抽樣分配爲

$$
p^{x}-p^{y} \cong N\left(0, p(1-p)\left(\frac{1}{n^{x}}+\frac{1}{n^{y}}\right)\right)
$$

其標準化分數爲

$$
Z=\frac{\hat{p}^{x}-\hat{p}^{y}}{\sqrt{\hat{p}(1-\hat{p})\left(\frac{1}{n^{x}}+\frac{1}{n^{y}}\right)}} \cong N(0,1),
$$

其中 $\hat{p}^{x}=\frac{x}{n^{x}}, \hat{p}^{y}=\frac{y}{n^{y}}, \hat{p}=\frac{x+y}{n^{x}+n^{y}}$

本研究為右尾檢定, 在顯著水準為 $\alpha$ 的情形下其拒絕域 $R$ 為

$$
\begin{aligned}
R & =\left\{\hat{p}^{x}-\hat{p}^{y} \mid Z>Z_{\alpha}\right\} \\
& =\left\{\hat{p}^{x}-\hat{p}^{y} \mid \frac{\hat{p}^{x}-\hat{p}^{y}}{\sqrt{\hat{p}(1-\hat{p})\left(\frac{1}{n^{x}}+\frac{1}{n^{y}}\right)}}>Z_{\alpha}\right\} \\
& =\left\{\hat{p}^{x}-\hat{p}^{y} \mid \hat{p}^{x}-\hat{p}^{y}>Z_{\alpha} \sqrt{\hat{p}(1-\hat{p})\left(\frac{1}{n^{x}}+\frac{1}{n^{y}}\right)}\right\}
\end{aligned}
$$

檢定結果若落入拒絕域中則拒絕 $H_{0}$, 表示滿意度比例 $\hat{p}^{x}$ 顯著高於重視度比例 $\hat{p}^{y}$, 表示教學品質是優良的。相反 的, 檢定結果若未落入拒絕域中則不拒絕 $H_{0}$, 表示滿意度 比例 $\hat{p}^{x}$ 顯著低於重視度比例 $\hat{p}^{y}$, 表示教學品質未能符合學 生的期望。

\section{教學品質評估程序}

為了方便評估教學品質, 本文訂定一個簡單的評估程 序, 這個如圖1所示, 包括有7大步驟：

步驟1：依體育教學品質模式來訂定體育教學品質教學 問卷題目。

步驟 2 ： 選定誤差值範圍（通常設定為 $5 \%$ 以下）與顯著 水準 $\alpha$ 值（通常設定為0.01或 $0.05 ） 。$

步䝒 3 ： 決定樣本數大小。若要求估計的誤差值在 $5 \%$ 以 下, 且在 $95 \%$ 的信賴水準下, 即

$$
\begin{aligned}
& P(|p-\hat{p}| \leq e)=1-\alpha, \text { 所以 } \\
& n=\left(\frac{Z_{\alpha / 2} \sqrt{p(1-p)}}{e}\right)^{2}
\end{aligned}
$$

其中 $\alpha=0.05, e=Z_{\alpha / 2} \sqrt{\frac{p(1-p)}{n}} \leq 0.05 ，$ 若以保守估計法取 $p=1 / 2$, 則

$$
n \geq \frac{Z_{\alpha / 2}^{2}}{e^{2}}[p(1-p)]=\frac{(1.96)^{2}}{(0.05)^{2}} \cdot \frac{1}{4}=384.16
$$

因此, 取樣本大小 $n=384$ 即可滿足取樣要求。

步驟4： 設定虚無假設及對立假設

$$
H_{0}: p^{x}-p^{y} \leq 0 \quad H_{a}: p^{x}-p^{y}>0
$$

步驟5：依隨機樣本的觀察值計算滿意度比例 $\hat{p}^{x}$ 與 重視度比例 $\hat{p}^{y}$, 作為統計檢定量,填入表4。

步驟6: 根據 $\hat{p}^{x} 、 \hat{p}^{y}$ 計算出p-value。

步㵵7: 依 $\mathrm{p}$-value 來判定滿意度比例 $\hat{p}^{x}$ 與重視度比 例 $\hat{p}^{y}$ 是否有落差存在, 當p-value $>\alpha$ 時, 則不 拒絕虚無假設 $H_{0}: p^{x}-p^{y} \leq 0$, 此時滿意度比 例 $\hat{p}^{x}$ 㙷著低於重視度比例 $\hat{p}^{y}$, 表示教學品質 未能符合學生的期望; 當 $\mathrm{p}-\mathrm{value}<\alpha$ 時, 則接受 對立假設 $H_{a}: p^{x}-p^{y}>0$, 此時滿意度比例 $\hat{p}^{x}$ 顯著高於重視度比例 $\hat{p}^{y}$, 表示教學品質符合學 生的期望。 
從表4可以説明檢定方法的應用, $p_{I}$ 標示“*”記號， 這表示第1個教學品質要項滿意度符合重視度, 也就是教學 品質符合學生的期望。而 $p_{2}$ 没有標示記號, 這表示第2個 教學品質要項教學品質未能滿足學生的期望。“*”記號可 以更細淢的應用, 我們將 $p-v a l u e$ 的檢定分為3個層次, 當 $p$-value $\leq 0.01$ 標示 “***”記號, 表示該項教學品質優良; 當 $p$-value $\leq 0.05$ 標示 “***記號, 表示該項教學品質普通; 當 $p$-value $\geq 0.05$ 則不標示記號, 表示該項教學品質不佳。

\section{結論}

隨著教育普及與多元化，如何提升教學品質一直是教 育界所關注的焦點。體育為教育的一環，體育教學也必須追 求卓越教學品質。在實務上, 以適切可行的方法評量教學品 質是必須強調的。本文提出一套完整的體育教學品質評估模 式, 此模式以「體育教學品質概念」作為評量體育教學品質 的內涵, 接著以二項分配的方式來衡量體育教學問卷要項的 滿意程度比例與重視程度比例, 最後本研究建構出一套檢定 滿意度比例與重視度比例之間落差的程序, 讓體育教學品質 的評量更為客觀。所以「體育教學品質評估模式」提供了 體育教學單位與教師評量體育教學品質一個簡單又方便的工 具。

\section{表4＼cjkstart體育教學品質要項統計值}

\begin{tabular}{cccc}
\hline 教學品質要項 & $\hat{p}_{. j}^{y}$ & $\hat{p}_{. j}^{x}$ & $p$-value \\
\hline 1 & $\hat{p}_{3}^{y}$ & $\hat{p}_{.3}^{x}$ & $p_{1}^{*}$ \\
2 & $\hat{p}_{3}^{y}$ & $\hat{p}_{.3}^{x}$ & $p_{2}$ \\
3 & $\hat{p}_{3}^{y}$ & $\hat{p}_{3}^{x}$ & $p_{3}^{*}$ \\
4 & $\hat{p}_{.4}^{y}$ & $\hat{p}_{.}^{x}$ & $p_{4}^{*}$ \\
$\vdots$ & $\vdots$ & $\vdots$ & $\vdots$ \\
$j$ & $\hat{p}_{. j}^{y}$ & $\hat{p}_{. j}^{x}$ & $p_{j}^{*}$ \\
$:$ & $:$ & $:$ & $:$ \\
$m$ & $\hat{p}_{. m}^{y}$ & $\hat{p}_{. m}^{x}$ & $p_{m}$ \\
\hline
\end{tabular}

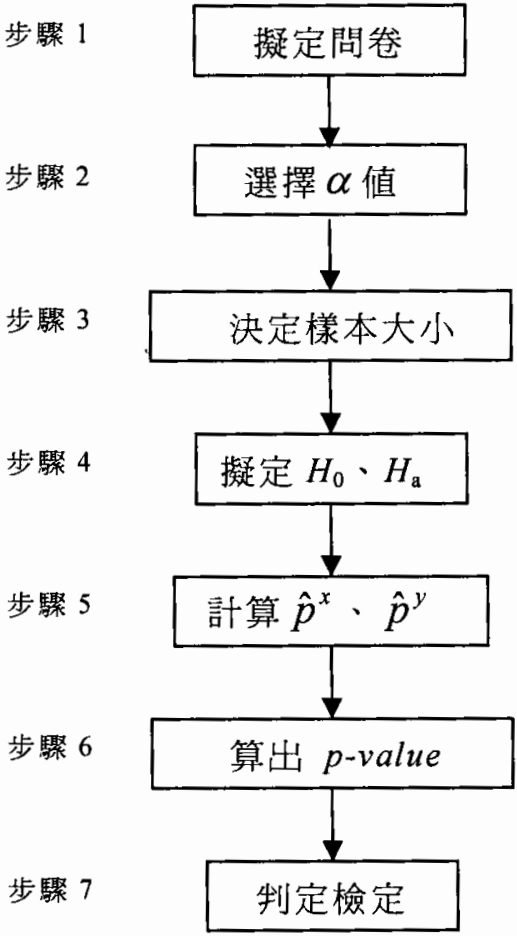

圖 1. 教學品質評估流程圖 


\section{參考文獻}

王俊貴（2001）。國民小學呚師對理想服務品質與實際服務 品質知覺差異之調查研究。未出版碩士論文, 台南市, 國立臺南敉育大學國民敎育研究所。

江義平（2000）。敎學服務品質衡量模式建構及分析之研 究, 亞太管理評論, 5卷1期, 95-115頁。

伍木成、梁隨燕、洪彰鴻、謝武進（2006）。以品質績效區 間衡量體育教學品質。僑光學報，27期，37-44頁。

邱子玲（2003）。我國高等教育服務品質差距分析之研究一 以淡江大學為例。未出版碩士論文, 台北縣, 淡江大學 教育政策與領導研究所。

周碩樑（1999）。高級工業職業學校服務品質內涵建構與實 證調查研究。未出版碩士論文, 國立台灣師範大學工業 教育研究所, 台北市。

吳春雨（2004）。六標準差應用於教學品質之研究。未出版 碩士論文, 台南縣, 南台科技大學工業管理研究所。

洪彰鴻（2004）。應用 PZB Gap Model 探討體育教學品質。 屏師運動科學學刊, 1期, 72-78頁。

洪彰鴻、李城忠（2004）。台北地區健身俱樂部服務品質與 健身消費者行為之研究。運動休閒管理學報, 1 卷 2 期, 141-158頁。

洪彰鴻、蘇榮基（2005a）。體育教學服務品質量表建構之 初探。體康學報, 11 卷1期, 65-70頁。

洪彰鴻、蘇榮基（2005b）。體育教學品質期望內涵之探 討。勤益學報，23卷 1期，57-71頁。

洪彰鴻、徐欽賢（2005）。論PZB服務品質概念之演進及國 內運動休閒之應用。勤益學報，23卷1期，167-180頁。

黃勇富（1999）。藉PZB模式之缺口改善以提升敉學品質。 品質管制月刊，63-65頁。
張俊郎、周昭宇（2001）：應用品質機能展開探討敉學品質 之改善。呚育與心理研究，24期，49-66頁.

簡珠紅（1993）。㸚學評鑑的內涵與實施。載於伍振䉆主 編：教育評鑑，173-189頁。

簡君蓉（2002）。國民中學學校服務品質缺口模式問卷發展 與應用之研究。未出版碩士論文, 南投縣, 國立暨南國 際大學教育政策與行政研究所。

陳謙東（2000）。呚育績效的統計分析與應用。未出版碩士 論文, 台北縣, 淡江大學應用統計研究所。

陳育君（2002）。應用PZB服務品質模式在國小資優般獨立 研究教學品質評鑑之研究。未出版碩士論文, 台東縣, 國立台東大學學育研究所。

饒達欽、鄭添財（1997）。談教師敉學品質。技術及職業教 育雙月刊，42期，7-11頁。

Parasuraman, A., Zeithaml, V. A., \& Berry, L. L. (1985). A Conceptual Model of Service Quality and Its Implications for Future Research. Journal of Marketing, 49(3), 41-50.

Parasuraman, A., Zeithaml, V. A. \& Berry, L. L. (1988). SERVQUAL:A multipule-item scale for measure consumer perceptions of service quality. Journal of Retailing, 64(1), 12-40.

Parasuraman, A., Zeithaml, V. A. \& Berry, L. L. (1991). Understanding customer expectation of service. Sloan Management Review, 39-48.

\section{連絡人}

洪彰鴻

地址：台灣台中縣太平市中山路一段215巷35號

國立勤益科技大學休閒產業管理系

National Chin-Yi University of Technology Office of Physical Education

No.35, Lane 215, Section 1,

Chung-Shan Road, Taiping City,

Taichung County, 411 Taiwan,

e-mail:hongjh@ncut.edu.tw 